\title{
Strategies to establish rapport during online management coaching
}

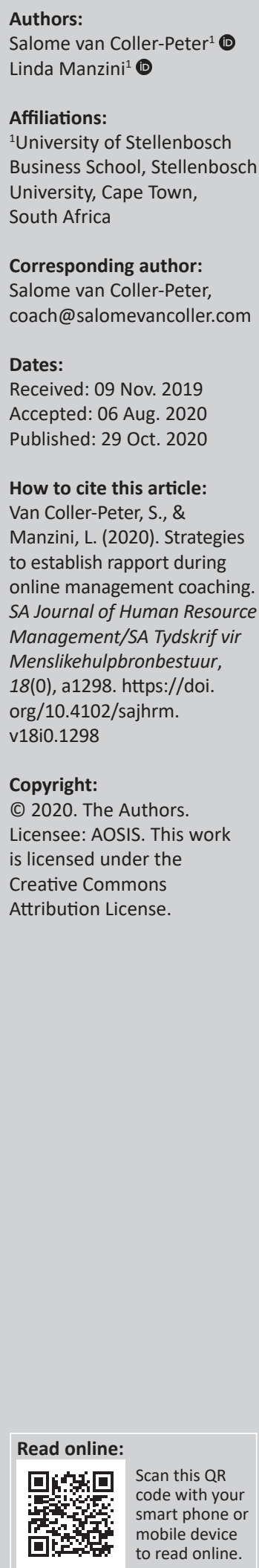

Orientation: Online coaching (via a range of technologies) is becoming a preferred option as more and more coaches and clients embrace technology-enabled environments. One of the fundamental skills of coaching is the ability of the coach to build rapport with the client.

Research purpose: The purpose of this study was to explore ways in which rapport can be established between the coach and the client during online management coaching.

Motivation for the study: The authors believe that the creation of rapport online between the coach and the client cannot be left to evolve naturally and that the building of rapport requires the parties to invest intentionally to create connection and chemistry. Hence, this question: What can be done to optimise the rapport between client and coach during e-coaching?

Research approach/design and method: To obtain primary data for this qualitative study, semi-structured interviews were conducted with six coaches and six clients who had experienced at least four online management coaching sessions without meeting the client or coach face to face.

Main findings: This article provides practical strategies on how to build rapport during online coaching. With explicit articulation and consistent application, these strategies can help to improve interpersonal connection between coach and client.

Practical or managerial implications: This study offers strategies to establish rapport between coach and client during online management coaching.

Contribution/value-add: The results of this study inform the practice of online coaching as well as the design of coaching programmes for the future.

Keywords: e-coaching; nonverbal cues; online interpersonal communication; online management coaching; rapport; verbal cues.

\section{Introduction}

Coaching as a profession is gaining momentum, and the use of technology to facilitate management coaching is becoming a preferred option. Sherpa Coaching's 2019 Executive Coaching Survey revealed that in the majority of cases, coaching was delivered using technology (Sherpa Coaching, 2019). The survey found that in $2019,32 \%$ of coaching was done face to face compared to $59 \%$ in 2012. According to this survey, most of the coaching was done using technology (telephone $25 \%$, webcam and Skype 25\%, email 8\% and video conferencing 10\%). However, the prevalence of technology has consequences for rapport development.

Building rapport with a client is a prerequisite in establishing a trusting and productive management coaching relationship. According to Clutterbuck and Hussain (2010, p. 156), 'Rapport is the core of the coaching relationship'. Without this rapport, there can be no genuine coaching relationship, making it difficult for clients to reach their full potential.

It is therefore essential to know what creates rapport between coach and client in a coaching relationship. According to Starr (2002, p. 993), the critical factors in rapport building are 'physical appearance; body language or gestures; quality of voice; language or use of words; and beliefs and values'. These nonverbal factors are much more feasible to work with, assess, maintain and achieve in a face-to-face coaching relationship. Research findings indicate that even today, consumers evaluate the trustworthiness of partners based on the first impression of the initial face-to-face experience (Chamberlin, 2000; McKnight, Cummings, \& Chervany, 1998). If this is the case, gaining insight into establishing rapport online becomes critical to ensure that effective coaching centred on rapport between coach and client is achieved. 
Several researchers have explored the growing trend to use modern technology in coaching (Frazee, 2008; Grant \& Zackon, 2004; ICF, 2007). Looking for research on the technology-facilitated delivery of coaching yielded various results relating to therapy rather than coaching (Blake Buffini \& Gordon, 2015; Weitz, 2014). The concerns addressed by these researchers included the effective functioning of the working alliance and the comparability to face-to-face interactions. Kanatouri and Geissler commented that 'Since coaching evolved as an industry in the 1990s, the target groups and application fields for coaching have multiplied' (2017, p. 715). Researchers like Clutterbuck and Hussain (2010), Boyce and Hernez-Broome (2010), Otte, Bangerter and Wüthrich (2014), and Kanatouri and Geissler (2017) reported that, in reality, practitioners of coaching make much more use of technology and that face-to-face sessions in real time are not the norm anymore.

No matter which of the various definitions of coaching you subscribe to, one aspect is always prevalent: the facilitation of learning. Learning is an essential part of the coaching process.

In an online management coaching relationship, the coach mainly relies on the quality of voice, intonation and use of language and words. The lack of nonverbal signals during online management coaching deprives participants of critical information about their communicator, such as character, attitude and emotions, which can lead to poor understanding and effectiveness, and constrained social communication. It may seem a paradox, but when they have the freedom offered by email communication, clients decide how much and what information to share.

Clients become freer to open themselves up when they are no longer forced to share their feelings in an intimate setting such as face-to-face counselling. They are free from the misunderstandings that could come from non-verbal communication in traditional counselling settings. Perhaps, the online environment allows clients to provide information that they would never reveal in direct contact with a counsellor.

By the time this study was conducted in 2016, limited research was available on how rapport is built during online management coaching and the underlying chemistry created between coach and client. Hence, this qualitative study aimed to explore ways in which rapport can be established between coach and client during online management coaching. Strategies to guide rapport development could contribute towards more productive interactions in an online coaching environment.

In the next section, a theoretical framework is provided based on what is already known about rapport building between coach and client during online management coaching. After that, a presentation of the empirical study follows. Semi-structured interviews were used to capture the experiences of the coaches and their clients. Finally, the article presents strategies on how to establish rapport during online management coaching.

\section{Theoretical framework}

The research and theoretical foundations relevant in exploring the establishment of rapport between coach and client online are reviewed below. The following terms are used interchangeably in this article: online management coaching, e-coaching, remote coaching, distance coaching and virtual coaching. In this section, the nature, benefits and challenges of online management coaching, the technology used and, in particular, the building of rapport, including verbal cues and nonverbal cues, are discussed.

\section{Nature, benefits and challenges of online management coaching}

Traditionally, coaching has been conducted face to face. Today, the upsurge of technology has enabled the emergence of online management coaching. Face-to-face coaching can be idiosyncratic and expensive, whereas coaching online enables organisations to offer effective coaching to more people at various levels, allowing coaching to be more constant, sizable and cost-efficient (Barbian, 2002; Charbonneau, 2002). Challenges related to the cost of time, travel and scheduling have given rise to the popularity of distance coaching, which involves conducting coaching from different physical locations using technologies such as telephones and computers (Ghods, 2009, p. 36). According to Hernez-Broome, Boyce and Whyman (2007), computermediated and distance technologies influenced coaching, historically conducted face to face. Frazee (2008, p. 90) discovered that $26 \%$ of a sample of 191 coaches interacted with clients at a distance with no face-to-face interaction. According to Berry (2005), all the coaches in her study (102 coaches) reported that they sometimes use the telephone to interact with clients, while $25 \%$ indicated that they rarely or never meet clients face to face.

\section{More recently the following has been reported:}

Popular publications and anecdotal evidence perceive distance coaching as a practical, creative and cost-effective coaching approach compared to face-to-face coaching as it decreases the costs associated with travel and time, and enhances productivity and knowledge. (Ghods, 2009, p. 36)

Frazee (2008, p. 53) agreed that e-coaching assists coaches and clients to enhance contact opportunities, despite challenges in terms of different geographic locations, time scheduling and competing demands.

As the discourse on e-coaching is recent, there is an apparent lack of consensus around its meaning. Coach and leadership expert David Clutterbuck (2010), co-founder of the European Mentoring and Coaching Council, defined e-coaching as a developmental partnership in which the learning dialogue is conducted online. An alternative definition considers e-coaching as a technology-mediated relationship 
between coach and client, to facilitate client growth (Boyce \& Hernez-Broome, 2010).

Online management coaching is sometimes referred to as 'just-in-time' coaching, being available as and when required, allowing greater flexibility for the coach and the client to interact when the need arises. E-coaching allows coaches to be more flexible, which is viewed by clients as leading to a successful coaching experience (Hall, Otazo, \& Hollenbeck, 1999). Ribbers and Waringa (2012, p. 31) concurred that within e-coaching, interaction moments could be flexibly arranged, ensuring continuity within the coaching relationship and facilitating lively interaction with numerous opportunities for feedback.

E-coaching also enables access to a bigger and more diverse pool of coaches (Frazee, 2008, p. 54). Stone (2004) said that as e-coaching was not constrained by time or location and was less dependent on face-to-face interaction, the matching of coach and client could be based more on compatibility and less on other demographics, location, or ease of access. E-coaching, therefore, allows an organisation to scale its coaching programme by tapping into a larger pool of coaches who are not limited by face-to-face requirements.

Some researchers believe that e-coaching deepens the level of engagement between coach and client because e-coaching may reveal insights hidden in face-to-face coaching (Frazee, 2008, p. 55). Ribbers and Waringa (2012, p. 32) stated that e-coaching reached the crux of the matter much quicker and facilitated greater depth than face-to-face coaching. It has also been noted that online communication tools may enable more candid and objective feedback owing to their ability to enhance a sense of anonymity and openness (Hamilton \& Scandura, 2003).

The separate physical locations of the coach and the client in e-coaching could pose various challenges. Some coaching activities, including rapport development, are sometimes encouraged and supported by the coach's visual cues like eye contact, nodding and smiling. According to Frazee (2008, p. 56), 'some learning requires implicit contextual information, gestural cues, or coordinating physical action'. The disadvantages, challenges and limitations of e-coaching, as cited by researchers, include the development of trust, the management of interpersonal issues and the ability to communicate effectively at a distance (Frazee, 2008, p. 56; Ghods, 2009, p. 42). In a study of executive coaching by Charbonneau (2002), eight out of 10 clients indicated that a trusting relationship was fundamental and could only be facilitated face-to-face, at least initially. Wenger (1998) concurred that it could be more challenging to develop trust at a distance. Communicating over a distance, therefore, increases the importance of alerting clients that they have been heard (Feldman, 2002). Hence, choosing the appropriate technology to use during online management coaching becomes critical.

\section{Technological modalities used in online management coaching}

Online management coaching uses various technological modalities to deliver a coaching experience to clients in different geographical locations. These technologies include coaching via video (Skype/Zoom), coaching via telephone, coaching via email, and coaching via chat line (WhatsApp and texting).

Traditionally, coaching used to be conducted face to face, but this has changed (Gregory \& Levy, 2010). Already, coaches are evolving their practices beyond face-to-face to include phone coaching, video conferencing, instant messaging and text communications, and email (Pascal, Sass, \& Gregory, 2015; Rossett \& Marino, 2005). Rossett and Marino (2005) highlighted many of the benefits of leveraging technology for coaching, noting that it eliminates geographic barriers and access to individuals with specialised expertise. E-coaching, therefore, puts one-on-one development support within reach of individuals in even the most remote locations. Technology-enabled coaching can also be more cost-effective than face-to-face coaching, eliminating the need for costly travel and time away from the office for the coach. It is essential that the:

[A] coach must decide on what modality to use given the situation and the tools available, as well as the coach's own and client's abilities, personality, preference, experience, and coaching philosophy. (Hernez-Broome et al., 2007; Pulley, 2006).

The technological modality chosen for e-coaching should, therefore, be aligned to establish rapport during online management coaching. It is also critical to choose a technology that both client and coach feel comfortable with and have access to.

Pascal et al., (2015) highlighted several advantages of technology-enabled coaching. One advantage is access to a large pool of potential coaches. The authors noted that virtual coaching eliminates geographic constraints to finding an effective coach-coachee match, thereby increasing the likelihood that the client would find the coach who best meets his or her needs. A second significant advantage is that technology-enabled coaching is convenient, flexible, timesaving and cost-effective. Pascal et al., (2015) therefore asked: Does the quality of the coaching experience suffer if the technology is used to replace face-to-face coaching sessions entirely? In other words, rather than merely focusing on the addition of technology, is the absence of face-to-face interaction, a detriment to the quality of coaching and relevant to client outcomes? This question triggered the authors' interest to answer an essential part of this question: Is rapport building in face-to-face coaching and e-coaching different or similar?

\section{Rapport}

Researchers have offered broad definitions of rapport. Common attributes emerging as key elements of rapport 
include chemistry, trust, mutual understanding, warmth and mutual respect (Boyce, Jackson, \& Neal, 2010; Ghods, 2009; Laborde, 1983; Tickle-Degnen \& Rosenthal, 1990). The coaching literature agrees that it is crucial to establish a partnership with the client based on confidentiality, trust, honesty and mutual respect as it enables coordination and buy-in about expectations and objectives (Ghods, 2009, p. 8). Rapport development is informed by appearance, body gestures, quality of voice, language or word use, beliefs and values (Starr, 2002, p. 992). The coaching literature seems to put the onus on the coach to establish and develop rapport with the client. According to Wycherley and Cox (2008, p. 45), the coach's competency to consider the client's predicament through empathy and understanding should enable the coach to overcome challenges in establishing rapport. Ghods (2009) explained that the coach's supportive skills - such as warmth, compassion, patience and empathy - are vital in building a strong coach-and-client relationship, two-way communication, the ability to pose powerful questions, active listening and understanding of the client's challenges and predicament. This view is affirmed by Starr (2002), stating that rapport is present in all forms of conversation, whether it is telephonic, written or face-to-face communication.

\section{Verbal cues and nonverbal cues}

Research conducted by psychologist Albert Mehrabian (Mehrabian \& Ferris, 1967) indicated that 7\% of communication is verbal, while $38 \%$ is based on intonation and $55 \%$ on body language. Berry, Pennebaker, Mueller and Hiller (1997) shared a different view, finding that verbal communication conveyed as much information as nonverbal behaviour. For the current study, verbal cues are defined as the spoken and language-based form of communication between individuals, including tone and quality of voice. Nonverbal cues refer to eye contact, gestures, physical appearance, body language, silence and listening.

Various researchers have examined the importance of verbal and nonverbal cues in building rapport between individuals. Verbal cues encompass choice of words, types of sentences and flexibility of speech, as well as how the person speaks to another (Isbister \& Nass, 2000, p. 253). Pitsounis and Dixon (1988) believed that the skill of encouragement was centred in verbal articulations that demonstrate acceptance, reinforce effort, or appreciate performance and contributions. During coaching via video and telephone modalities, verbal articulations by the coach could serve as a source of encouragement for clients in building remote interpersonal relationships. A study performed by Walther, Loh, \& Granka (2005) illustrated that individuals adapted to online communication by infusing verbal messages with information about the communicator's character, emotion and attitude, thus allowing improved relationship-based communication to surface. This view is supported by Ribbers and Waringa (2012, p. 26) who found that language in e-communication could be enriched through the use of stylistic tools that help to express emotions and state of mind, such as emoticons (smiley face), sound words ('hmm' or 'ugh'), action words, font (boldface to emphasise) and capital letters (shouting). These may be open to interpretation, especially at the beginning of the coaching relationship. However, as client and coach get to know each other better, they get to know each other's communication queues.

The very lack of nonverbal cues online affords possibilities to accentuate one's identity and interpersonal relations (Walther \& Parks, 2002). Lack of visual social information about a conversation partner during phone, chat and email communication promoted participation, equality, friendliness, openness and honesty (Ribbers \& Waringa, 2012, p. 27).

Nonverbal cues include body posture and movement as the person interact with others (Isbister \& Nass, 2000, p. 253; Gallagher, 1992). Nonverbal communication - such as gestures, facial expressions, body movement, looks and physical appearance - communicate messages between people (Burgoon, Guerrero, \& Manusov, 2011, p. 215). In e-coaching, there are no nonverbal cues, except if the coaching is conducted via video, which can still limit nonverbal cues.

Nonverbal cues came first in our evolutionary journey as humans and first in our ontological development as people; and they were the first signals we responded to in our initial interaction with humanity (Burgoon et al., 2011, p. 218). Research findings from neuroscience revealed that nonverbal signals such as facial expressions activated brain structures, resulting in the judgement of the sender of the messages (Wood, 2006). Perceived nonverbal cues, therefore, influence the assessment of the trust-related characteristics of the sender and are critical in the development of rapport (Wood, 2006). Tickle-Dengen and Rosenthal (1990) confirmed that nonverbal behaviour or cues are essential in the emergence of rapport between individuals, as it served as a barometer that measures the climate surrounding the interaction, for example, a smile during a friendly encounter. According to Laborde (1983, p. 283), the fundamental part of developing rapport is often accomplished nonverbally. Ribbers and Waringa (2012, p. 23) offered an alternative view of the contribution of nonverbal cues in developing rapport in a coaching relationship, articulating that it is a myth that body language and eye contact are fundamental in creating an excellent coach-client relationship.

\section{Research methodology}

This research aimed to identify strategies to establish rapport during online management coaching. The research was qualitative, aiming to study human action from the angle of the active participants themselves (Babbie \& Mouton, 2012, p. 270). The research intended to explore, make sense of and describe the coach and client's perspective on rapport building during e-coaching. 


\section{Research approach}

The research was conducted from the perspective of social actors, namely coaches and clients, in understanding their experience in establishing and developing rapport during online coaching. In this context, Bloomberg and Volpe (2012, p. 27) stated that qualitative research was best placed to enhance understanding of social activity from the viewpoint of the participants, through exploration, description and discovery. This research, therefore, attempted to understand how coaches and clients experienced and facilitated rapport during e-coaching. The seven stages of the interview process by Kvale (1996, p. 88) - namely thematising, designing, interviewing, transcribing, analysing, verifying and reporting - were followed and deemed most aligned with the research process.

\section{Sample}

The broad definition of the population for this research is all coaches and clients who have experienced e-coaching. The researcher used convenience and random sampling to select coaches and clients from a base of virtual and e-coaching networks. The participants did not belong to an organisation and were only known to the researcher through informal networks and a common interest in e-coaching. The key criterion in selecting the sample was the completion of at least four or more e-coaching sessions with a previously unknown coach or client. Before the e-coaching sessions, the coach and client had to be unknown to each other to ensure a clear foundation on which to build rapport based on initial human interaction and first impressions.

According to Bloomberg and Volpe (2012, p. 104), purposeful sampling is aimed at selecting scenarios that are fertile in information, and that would derive insight and understanding about the phenomenon being investigated. A sample of six coaches and six clients with adequate experience in giving and receiving e-coaching was chosen for the semi-structured interviews. The participants were selected based on age (ranging from 30 to 60 years), gender (three males and nine females), ethnic diversity (seven white people and five persons of mixed race), coaching experience (coaches with three to 12 years of experience) and e-coaching sessions received (clients who have received seven to 34 sessions of e-coaching). The locations of the participants were geographically dispersed and included North America, Scotland, Senegal, South Africa and Zimbabwe.

\section{Data collection and measuring instrument}

Based on the insights and information gained during the literature review, semi-structured questionnaires were designed for the coaches and the clients. The interviews were conducted one on one mainly, via Skype or Zoom, in line with the research topic regarding virtual connection, lasting approximately $45 \mathrm{~min}$ to $60 \mathrm{~min}$.

The initial interviews for both coaches and clients served as pilots, enabling refining of questions. The interview questionnaire could be changed as the interviews progressed to gain depth without bias (Maykut \& Morehouse, 1994). Separate questionnaires were designed for the coaches and the clients, exploring how rapport was established during the e-coaching. The following were some of the questions posed to the participants:

1. What made you choose e-coaching?

2. How was your experience with e-coaching?

3. Do you think there was rapport between you and the client/coach?

4. What led you to believe that there was rapport?

5. What were the key factors that enabled you to build rapport during e-coaching?

6. How did you promote rapport building?

7. How did the client/coach demonstrate that he/she had rapport with you?

Ethical clearance was obtained from the Departmental Ethics Screening Committee (DESC) of the University of Stellenbosch Business School before the fieldwork commenced.

\section{The credibility of the research findings and data analysis}

Various strategies were applied to ensure credibility concerning objectivity and quality,t Authenticity was promoted through the verification of transcripts with the participants. Triangulation was achieved by matching, comparing and analysing data collected through the research literature, leading to the identification of common trends. Direct quotes from the participants helped to illustrate the findings from this research, enabling readers to draw insights and transfer these to their contexts.

The transcribed data was organised into themes through a coding process, leading to data portrayed in figures, tables and discussions - as guided by Creswell (2007, p. 148). Basic coding was done manually, reviewing each transcript in detail, highlighting and recording all keywords in a separate table. The transcript was read at least three times to make sure that nothing had been omitted. The process was repeated with all the other transcripts. The codes were then paired to determine the main categories, themes and subthemes. The next step was to list the research objectives and the interview questions in a table to identify categories, themes and subthemes from the transcribed data. Findings were drawn from the analysis of concepts, patterns, segments and trends emerging from the data, as guided by Babbie and Mouton (2012, p. 492). These findings are presented in the following section.

\section{Research findings}

Both the coaches and the clients reflected and shared ways that promoted rapport building during online management coaching. Some of these reflections are presented in this section.

Virtual coaching allows the coach to decide in advance on the technological modality to be used in the coaching relationship 
taking into account the coaching situation and the tools available, including the capabilities, personality, preference, experience and coaching philosophy of both the coach and the client (Hernez-Broome et al., 2007; Pulley, 2006). For some participants, fully functional technology played a crucial role in building rapport during online management coaching, as captured below:

'... the connectivity is a big one, because if connectivity drops, then the rapport fails.' (Client B)

'I use all the platforms, electronic platforms in support of the client, and where it is convenient for them and myself to be able to meet. But, what it does for me, it helps maintain engagement and the intensity of the coaching with the client.' (Coach D)

Participants noted the ability of the coach or the client, to be honest, authentic, comfortable with self and relaxed as promoting rapport. Although these factors are considered as general requirements in a coaching relationship, in virtual coaching, they become more critical because of the absence of visual signals. Ribbers and Waringa $(2012$, p. 27) stated that the absence of visual social information about a conversation partner during phone, chat and email communication enhanced participation, equality, friendliness, openness and honesty. Participants' views on how authenticity contributes positively towards rapport building are shared below:

'Be authentic. We are who we are and don't try to pretend to the coach.' (Client C)

'You are looking for genuine, authentic connection in the responses of the client ...' (Coach D)

Some participants identified honesty as one of the factors in enhancing rapport building:

'I think honesty is key, and being clear from the very beginning of what your expectations are of the client, and also allowing them to state what their expectations of you.' (Coach A)

'If I cannot give her [coach] honesty, then how can I expect for her to be able to guide me on this journey?' (Client A)

According to Jackson, Boyce and Neal (2012, p. 202), the credibility of the coach inspired hope and confidence in the coaching process. In virtual coaching, credibility could be promoted by sharing and discovering personal experiences. Personal stories and interests were viewed as rapport promoters online, with some participants expressing the following insights:

'So, storytelling becomes more powerful because the story transcends the space.' (Coach C)

'Yes, there was humility in that he shared; the rapport was created through sympathy, and sharing of experiences.' (Client F)

Coaches and Mentors of South Africa (COMENSA) (n.d.) emphasises the importance of creating a safe space in a coaching relationship in which clients could courageously explore their inner and outer thinking. Assurance of a safe space online requires constant and explicit articulations during coaching sessions as parties establish a trusting relationship. Frazee (2008) reported on a study indicating that building rapport can be challenging when coaching over a distance; at the same time, technology offers increased accessibility and frequency of communication, which can potentially facilitate a more human process than face-to-face coaching. He also pointed out that the obstacles associated with telephone coaching, such as the lack of visual cues, can be overcome by verbalising the process to the client and by paying attention to the subtle parts of the conversation (Frazee, 2008). Some of the participants highlighted a safe space as a factor that promoted rapport for them during online coaching:

'... sometimes delving into very personal things that they share with you, and automatically there needs to be that understanding that whatever is said you are in a safe space.' (Coach B)

'It is a safe space, to be vulnerable and to be willing to explore new possibilities.' (Client B)

The safe space created during online management coaching enables in-depth listening. Some coaches and clients shared how listening helped to accentuate rapport during e-coaching conversations, in line with some of the articulations shared by researchers. Communicating over a distance increases the importance of alerting clients that they have been heard (Feldman, 2002). According to McLaughlin (2013, p. 10), telephone coaching is dependent on the coach's listening skills:

'... he made me understand that he listened to me, by summarising, when I finished with, even when we start new sessions, he would summarise what we did last time. And that made me feel very important.' (Client F)

'I find that coaching virtually has a lot to do with listening and connecting deeply without having the benefit of the visual cues.' (Coach C)

Listening and hearing are, therefore, of paramount importance during coaching online, and various ways could be explored by the coach to absorb information from the client. Participants reflected on how touching base, checking in, and feedback during e-coaching facilitated a platform to listen, leading to further enhancement of rapport, as captured below:

'You check in with the client anything that you get about them; you check in with them to verify, confirm, reconfirm certain things.' (Coach D)

'I touch base with my client in the sense that I ask them if what we are going through is sitting well with them. Do they have a clearer understanding of where they are?' (Coach B)

'I would advise clients just to be willing to give the coach feedback ...' (Client B)

The coaching conversation and information shared should be safeguarded by confidentiality, more so during online management coaching. The issue of confidentiality and being free from judgement surfaced as a stimulant in rapport building online. The coaching literature confirmed that it was critical to forming a partnership with the client based on confidentiality, trust, honesty and mutual respect as it facilitated harmonisation of coaching expectations and objectives (Ghods, 2009, p. 8): 
'I try to make sure that people understand that this conversation is confidential and that they can trust me with the information, etc.' (Coach C)

'Yes, in my view, in general, confidentiality is important because you can maybe share sensitive information on yourself or others ...' (Client D)

In virtual coaching, the very lack of nonverbal signals afforded possibilities to promote identity and interpersonal relations online (Walther \& Parks, 2002). It is therefore essential for both coaches and clients in a virtual coaching setting not to make assumptions but instead verbalise an understanding, situation or uncertainty. Some of the coachees believed this helped to build rapport in e-coaching:

'With virtual coaching so much is outside of the visual framework of both parties, and sometimes you have to verbally state what is going on.' (Client B)

'Let the client walk their own path and not assume that what you determined as levels of rapport are the same levels of rapport that the client has.' (Coach D)

Verbal cues - like the spoken word, the use of language and the tone of voice - in building rapport during e-coaching were mentioned as rapport enhancers (Isbister \& Nass, 2000, p. 253). The participants highlighted the role that verbal cues play in facilitating interpersonal relationships online:

'You can understand how I feel, and you can hear emotions in my voice when I share it with you.' (Client A)

'The coach still has access to things such as the client's language, tone of voice, the pace of words used, the description and so forth.' (Coach F)

'So the rapport can be established in the email, in the tone of the email, even in emails reflecting the client's language.' (Coach E)

Some participants identified the flow of conversation as a facilitator of rapport building, that is, how the conversation was being conducted:

'So the word that comes to mind is rhythm. The rhythm of the conversation which is a little bit of mirroring in our rhythm.' (Coach E)

'So, when the coach says, "What I am actually hearing you say, is ..." Or, "what I hear you say is this ..." And, "What I am getting from you that you are not saying is the following ..." So, those kinds of conversations, then I know that although the coach is miles away, they are present to who I am.' (Client B)

'I think when we were able to have conversations, the conversations flowed quite nicely, so I would say there was rapport.' (Coach B)

According to Ghods (2009, p. 9), coaching researchers acknowledged the coach's supportive skills - such as warmth, compassion, patience and empathy - as vital in building a strong coaching relationship. Also, coaching researchers acknowledged the coach's relationship with the client, two-way communication, the ability to pose powerful questions, active listening and an understanding of the client's challenges and predicament as key to building sound relationships. These attributes are centred in the coach's experience. Some participants viewed rapport as being encouraged by passion, commitment and experience from both the coach and the client, as presented below:

'You have to be passionate, and she [coach] was very passionate, and she was experienced as well, and I felt that she was experienced, I could learn from her.' (Client D)

'I think the client's passion for achieving his goal and that passion kind of grew commitment to achieve it.' (Coach F)

Some participants regarded the ability to use a sense of humour creatively as one of the factors that helped with rapport building online. Ribbers and Waringa (2012, p. 62) stated that one of the strategies geared towards building closer connections between coach and client, and that could be applied in e-coaching, is the use of a sense of humour:

'Sense of humour and a smile go a long way. It must be a very interesting conversation.' (Client C)

'When there's an opportunity to be humorous, share a joke or comment.' (Coach F)

Some participants identified clarity on guidelines, expectations and parameters upfront as instrumental in promoting rapport online:

'I think by explaining early the boundaries, boundaries is not the right word, but how we're going to connect and how this is going to work, particularly if the client may be using the virtual world for the first time.' (Client C)

'The client needs to know upfront what the parameters are ...' (Coach B)

The research findings outlined in this section helped to identify strategies to establish rapport between coach and client during online management coaching. These strategies are presented in the conclusion section that follows.

\section{Conclusion}

The emergence of online communication has created complexity and stimulated debate on how interpersonal relationships, in particular rapport, are established online. For the coaching fraternity, electronic communication is particularly important as they need to create chemistry between coach and client. The lack of nonverbal cues during e-coaching, save for limited visuals on video coaching, has led to the following question: What can be done to optimise the rapport between client and coach during e-coaching?

The participants highlighted the factors that assisted them in promoting rapport building during e-coaching. Based on these findings, this article identified the following strategies to establish rapport between coach and client during e-coaching:

- Online technology: Ensure that the chosen technological modality is functional, comfortable and compatible with both parties and the coaching environment.

- Authenticity and honesty: Both parties need to be reliable and have the ability to be their natural selves without being seen as trying too hard. 
- Personal storytelling: Include sharing of personal and similar experiences.

- Safe space: Create and hold a sacred space for the coaching conversation.

- Listening: Ensure that there is enough capacity to be an attentive and in-depth listener to hear what is not being said.

- Confidentiality and non-judgement: Ensure privacy for the conversation and be objective without judging.

- Check-in and feedback: Constantly seek, confirm and affirm information while providing feedback.

- Suspension of assumptions: Have no assumptions and verbally articulate thoughts and actions.

- Tone of voice and language: Ensure creative use of words, sentences, speech and language.

- Flow of conversation: Aim for a natural flow and buildup of the conversation.

- Passion, commitment and experience: Use passion, commitment and experience to support the interaction and engagement of the parties.

- Sense of humour: Create an exciting coaching conversation through humour.

- Setting of guidelines, expectations and boundaries: Both parties must have clarity up front on how the coaching engagement will be conducted as well as the end goal.

These strategies, or a combination thereof, with explicit articulation and consistent application will enable rapport to be established between coach and client in an online environment. The presence of rapport in coaching facilitates a sufficient learning experience, a sense of connection and closeness to bridge the social distance between coach and client online. The strategies also assist in compensating for the deficit of non-verbal cues during online management coaching. This study, therefore, offers strategies to establish rapport between coach and client during online management coaching.

\section{Acknowledgements Competing interests}

The authors have declared that no competing interest exists.

\section{Authors' contributions}

The main author was S.V.C.-P., and the second author was L.M.

\section{Ethical consideration}

The Departmental Ethics Screening Committee of the University of Stellenbosch Business School (USB DESC) (SU-HSD-0021387).

\section{Funding information}

This research received no specific grant from any funding agency in the public, commercial or not-for-profit sectors.

\section{Data availability statement}

Data sharing is not applicable to this article as no new data were created or analysed in this study.

\section{Disclaimer}

The views and opinions expressed in this article are those of the authors and do not necessarily reflect the official policy or position of any affiliated agency of the authors.

\section{References}

Babbie, E., \& Mouton, J. (2012). The practice of social research. Cape Town: Oxford University Press Southern Africa.

Barbian, J. (2002). A little help from your friends: An employee with ample job knowledge and experience is a trainer waiting to happen. Training, 39(3), 38-56.

Berry, D.S., Pennebaker, J.W., Mueller, J.S., \& Hiller, W.S. (1997). Linguistic bases of social perception. Personality and Social Psychology Bulletin, 23(5), 526-537. https://doi.org/10.1177/0146167297235008

Berry, R.M. (2005). A comparison of face-to-face and distance coaching practices: The role of the working alliance in problem resolution. Unpublished doctoral dissertation. Atlanta, GA: Georgia State University.

Blake Buffini, K., \& Gordon, M. (2015). One-on-one support for crisis intervention using online synchronous instant messaging: Evaluating working alliance and client satisfaction. British Journal of Guidance \& Counselling, 43(1), 105-116. https://doi.org/10.1080/03069885.2014.987723

Bloomberg, L.D., \& Volpe, M. (2012). Completing your qualitative dissertation: A roadmap from beginning to end (2nd edn.). Thousand Oaks, CA: Sage.

Boyce, L.A., \& Hernez-Broome, G. (2010). E-coaching: Consideration of leadership coaching in a virtual environment. In D. Clutterbuck \& Z. Hussain (Eds.), Virtual coach, virtual mentor (pp. 139-174). Charlotte, NC: IAP Information Age Publishing.

Boyce, L.A., Jackson, J.R., \& Neal, L.J. (2010). Building successful leadership coaching relationships: Examining impact of matching criteria in a leadership coaching program. Journal of Management Development, 29(10), 914-931. https://doi. org/10.1108/02621711011084231

Burgoon, J.K., Guerrero, L.K., \& Manusov, V. (2011). Nonverbal signals. In M.L. Knapp \& J. Daly (Eds.), Handbook of interpersonal communication. Thousand Oaks, CA: Sage Publishing.

Chamberlin, C.R. (2000). Nonverbal behaviors and initial impressions of trustworthiness in teacher-supervisor relationships. Communication Education, 49(4), 352-364. https://doi.org/10.1080/03634520009379223

Charbonneau, M.A. (2002). Participation self-perception about the cause of behavio change from a program of executive coaching. Unpublished doctoral dissertation. Los Angeles, CA: Alliant International University.

Clutterbuck, D., \& Hussain, Z. (2010). Virtual coach, virtual mentor. Charlotte, NC: Information Age Publishing.

Coaches and Mentors of South Africa (COMENSA). (n.d.). What is COMENSA? Retrieved June 11, 2016 from www.comensa.org.za/ABOUT_US/

Creswell, J.W. (2007). Qualitative inquiry and research design: Choosing among the five traditions (2nd edn.). Thousand Oaks, CA: Sage.

Feldman, D.A. (2002). Distance coaching. Training and Development, 56(9), 54-56.

Frazee, R.V. (2008). E-coaching in organizations: A study of features, practices, and determinants of use. Unpublished doctoral dissertation. San Diego, CA: San Diego University.

Gallagher, P.E. (1992). Individual differences in nonverbal behavior: Dimensions of style. Journal of Personality and Social Psychology, 63(1), 133-145. https://doi. org/10.1037/0022-3514.63.1.133

Ghods, N. (2009). Distance coaching: The relationship between the coach-client relationship, client satisfaction, and coaching outcomes. Unpublished doctoral dissertation. San Diego, CA: San Diego University.

Grant, A.M., \& Zackon, R. (2004). Executive, workplace and life coaching: Findings from a large-scale survey of International Coach Federation members. International Journal of Evidence Based Coaching and Mentoring, 2(2), 1-15.

Gregory, J.B., \& Levy, P.E. (2010). Employee coaching relationships: Enhancing construct clarity and measurement. Coaching: An International Journal of Theory, Research and Practice, 3, 109-123. https://doi.org/10.1080/17521882. 2010.502901

Hall, D.T., Otazo, K.L., \& Hollenbeck, G.P. (2000). Behind closed doors: What really happens in executive coaching. Organizational Dynamics, 27(3), 39-53. https:// doi.org/10.1016/S0090-2616(99)90020-7

Hamilton, B.A., \& Scandura, T.A. (2003). E-Mentoring: Implications for organizational learning and development in a wired world. Organizational Dynamics, 31(4) 388-402. https://doi.org/10.1016/S0090-2616(02)00128-6

Hernez-Broome, G., Boyce, L.A., \& Whyman, W. (2007). Critical issues of coaching with technology. In E-coaching: Supporting leadership coaching with technology. 
Symposium conducted at the 22nd Annual Conference of the Society for Industrial and Organizational Psychology, New York, NY.

International Coach Federation (ICF). (2007). Global coaching study: Final report Retrieved June 4, 2016 from www.coachfederation.org/coachingstudy2007.

Isbister, K., \& Nass, C. (2000). Consistency of personality in interactive characters: Verbal cues, non-verbal cues, and user characteristics. International Journal of Human-Computer Studies, 53(2), 251-267. https://doi.org/10.1006/ijhc. 2000.0368

Jackson, R.J., Boyce, L.A., \& Neal, L.J. (2012). Eharmony, match.com, plentyoffish Have you considered matching to support your client-coach relationships? In E. De Haan \& C. Sills (Eds.), Coaching relationships: The relational coaching field book. Oxfordshire: Libri Publishing.

Kanatouri, S., \& Geissler, H. (2017). Adapting to working with new technologies. In G. Spence \& D. Drake (Eds.), The SAGE Handbook of Coaching (pp. 715-730). London: Sage.

Kvale, S. (1996). Interviews: An Introduction to qualitative research interviewing. London: Sage Publications.

Laborde, G.Z. (1983). Influencing with Integrity. Palo Alto, CA: Syntony Publishing.

Maykut, P., \& Morehouse, R. (1994). Beginning qualitative research: A philosophic and practical guide. London: The Falmer Press.

McKnight, D.H., Cummings, H.L., \& Chervany, N.L. (1998). Initial trust formation in new organizational relationships. Academy of Management Review, 23(3), 473-490. https://doi.org/10.5465/amr.1998.926622

McLaughlin, M. (2013). Less is more: The executive coach's experience of working on the telephone. International Journal of Evidence Based Coaching and Mentoring. Special issue 7 (June), 1-13.

Mehrabian, A., \& Ferris, S.R. (1967). Inference of attitudes from nonverbal communication in two channels. Journal of Consulting Psychology, 31(3), 248. https://doi.org/10.1037/h0024648

Otte, S., Bangerter, A., Britsch, M., \& Wüthrich, U. (2014). Attitudes of coaches towards the use of computer-based technology in coaching. Consulting Psycholog Journal: Practice and Research, 66(1), 38-52. https://doi.org/10.1037/a0035592

Pascal, A., Sass, M., \& Gregory, J.B. (2015). I'm only human: The role of technology in coaching. Consulting Psychology Journal: Practice and Research, 67(2), 100-109. https://doi.org/10.1037/cpb0000025
Pitsounis, N.D., \& Dixon, P.N. (1988). Encouragement versus praise: Improving productivity of the mentally retarded. Individual Psychology, 44(4), 507-512.

Pulley, M.L. (2006). Blended coaching. In S. Ting \& P. Scisco (Eds.), The center for creative leadership handbook of coaching (pp. 347-378). San Francisco, CA: John Wiley \& Sons.

Ribbers, A., \& Waringa, A. (2012). E-Coaching: Theory and practice for a new online approach to coaching. Amsterdam, NL: Uitgeverij Boom Nelissen.

Rossett, A., \& Marino, G. (2005). If coaching is good, then e-coaching is...'. Training Development, 59(11), 46-49.

Starr, J. (2002). The coaching manual. London: Pearson Education Limited.

Stone, F. (2004). The mentoring advantage: Creating the next generation of leaders. Chicago, IL: Dearborn Trade Publishing.

Sherpa Coaching. (2019). The Sherpa Executive Coaching Survey Report. Retrieved September 30, 2019 from https://www.sherpacoaching.com/pdf_files/2019 Executive_Coaching_Survey_Summary_Report.pdf

Tickle-Degnen, L., \& Rosenthal, R. (1990). The nature of rapport and its nonverbal correlates. Psychological Inquiry, 1(4), 285-293. https://doi.org/10.1207/ s15327965pli0104_1

Walther, J.B., Loh, T., \& Granka, L. (2005). Let me count the ways the interchange of verbal and nonverbal cues in computer-mediated and face-to-face affinity. Journal of Language and Social Psychology, 24(1), 36-65. https://doi. org/10.1177/0261927X04273036

Walther, J.B., \& Parks, R.M. (2002). Cues filtered out, cues filtered in: Computermediated communication and relationships. Retrieved September 30, 2016 from http://www.researchgate.net/publication/239489124

Weitz, P. (2014). Psychotherapy 2.0: Where psychotherapy and technology meet. London: Karnac Books.

Wenger, E. (1998). Communities of practice and social learning systems. Organization, 7(2), 225-246. https://doi.org/10.1177/135050840072002

Wood, J.A. (2006). NLP revisited: Non-verbal communications and signal of trustworthiness. Journal of Personal Selling \& Sales Management, 26(2), 197-204. https://doi.org/10.2753/PSS0885-3134260206

Wycherley, I.M., \& Cox, E. (2008). Factors in the selection and matching of executive coaches in organisations. Coaching: An International Journal of Theory, Research and Practice, 1(1), 39-53. https://doi.org/10.1080/17521880701878075 